\title{
Optimal Cutoffs of Grip Strength for Definition as Weakness in the Elderly
}

\author{
Renwei Dong, Qi Guo, Jiazhong Wang \\ Department of Rehabilitation and Sports Medicine, Tianjin Medical University, Tianjin, China \\ Email: 821481532@qq.com
}

Received October 2014

\begin{abstract}
Objective: To indentify Optimal cutoffs of grip strength for definition as weakness in the elderly. Methods: Our study population comprised 1317 subjects (mean \pm SD age: $67.6 \pm 6.0$ years; 44.3\% men) from the Hangu area of Tianjin, China. Data collection includes general physical examination, biochemical indicators and questionnaire. Mobility limitation was defined as a 4-m walking speed $<0.8 \mathrm{~m} / \mathrm{s}$ and grip strength represents muscle strength. According to the ROC curve model, the cut-off point of grip strength was calculated, when mobility limitation was selected as the target variables. Results: According to the results of ROC curve, In man, grip strength is lower than $32.45 \mathrm{~kg}$, the strength is weaker, Sensitivity is $79.7 \%$ and Specificity is $64.9 \%$, the AUC is 0.764 ( < 0.001); In women, grip strength is lower than $18.20 \mathrm{~kg}$, the strength is weaker, Sensitivity is $53.3 \%$ and Specificity is78.1\%, the AUC is $0.703(p<0.001)$. Conclusions: Cut points for weakness derived from this large, diverse sample of older adults may be useful to identify populations who may benefit from interventions to improve muscle strength and function.
\end{abstract}

\section{Keywords}

Cutoffs, Elderly People, Grip Strength, Weakness

\section{Introduction}

Muscle weakness is related to poor physical performance and incident mobility limitations among older adults [1]. Weakness is considered a key element of frailty [2] and, increasingly, of sarcopenia [3]. Although the association between weakness and functional limitations strong, there is no consensus regarding a cut point for identification of risk for functional problems. In order to identify population subgroups in whom weakness is a potential contributor to functional limitations, it is necessary to determine what constitutes a clinically relevant degree of weakness.

\section{Participants and Method}

\subsection{Participants}

Our study population comprised residents of the Hangu area of Tianjin, China, aged $\geq 60 \mathrm{y}$, who joined the national free physical examination program. All subjects were invited to participate in a comprehensive geriatric 
assessment, with the exception of those with a disability that affected the basic activities of daily living, and factors, which influenced grip strength level, such as stroke、 cancer and hand injury, and those who could not carry out performance-based assessments. The final study population comprised 1317 subjects (mean \pm SD age: $67.6 \pm 6.0$ years; $44.3 \%$ men), after those with data deficiencies $(n=92)$ were excluded.

\subsection{4-m Speed Measurement [4]}

Participants were instructed to stand with both feet touching the starting line and to begin walking at their usual pace after a verbal command was given. The time between activation of the first and the second photocell was measured and the average speed of two walks was recorded.

\subsection{Definition of Mobility Limitation}

Walking speed was assessed by trained nurses, where participants were requested to walk 2.4 or 6 meters a self-selected speed [5]. The length of the walk was determined by asking the participants how fast they normally walk. Subjects who rated themselves as fast or normal walkers did the longer walk and slow or very slow self-rated walkers did the shorter walk. At home visits, the shorter walk was always conducted due to space restrictions. For the analyses, the walking speed reflects the time from whichever walk was performed by the participant. Subjects who were unable to walk without personal support received the worst possible score, i.e. $0 \mathrm{~m} / \mathrm{s}$. Mobility limitation was defined as a walking speed, $0.8 \mathrm{~m} / \mathrm{s}$ because it may reflect underlying disease [6] [7].

\subsection{Statistical Analyses}

Data with a normal distribution are expressed as the mean \pm SD, whereas data with an abnormal distribution are expressed as the median, with the $25 \%$ - $75 \%$ inter quartile range given in parentheses. Categorical variables are expressed as proportions. Receiver operating characteristic (ROC) curve analysis was performed to determine the optimal grip strength cut-off values, with the presence of mobility limitation as outcome variable. The ROC curve was agraph of sensitivity plotted against (1-specificity) overall possible diagnostic cut-off values. The optimal cut-off values were obtained from the maximal Youden's Index, calculated as (sensitivity + specificity -1 ) and the best combination of sensitivity and specificity.

\section{Results}

\subsection{General Characteristics of the Study Population}

The clinical characteristics of the study participants are presented in Table 1. The cross-sectional analyses included data on 1317 participants (596men and 721 women; mean \pm SD age: $67.6 \pm 6.0$ years). In terms of fitness, male grip strength coefficient and 4-m walking speed is superior to female. Compared to men, women are more likely to have mobility limitation (men $13.3 \%$, women $18.7 \%$ ). The percentage of at least 1 CDR in men and women, respectively, were $57.0 \%$ and $72.1 \%$, The percentage of at least 2 CDR and 3 CDR in women is both higher than in men.

Figure 1 provides plots of the association between maximum grip strength and gait speed in men and women, Visual inspection of the LOESS curves provided little evidence of a clear threshold effect of strength on continuous gait speed.

\subsection{The Optimal Cut-Off Point of Grip Strength and the Area under the Curve (AUC) for Reflecting Mobility Limitation}

The optimal cut-off point of grip strength and the area under the curve (AUC) for reflecting mobility limitation are presented in Table 2. According to the results of ROC curve, In man, grip strength is lower than $32.45 \mathrm{~kg}$, the strength is weaker, Sensitivity is $79.7 \%$ and Specificity is $64.9 \%$, the AUC is 0.764 ( $p<0.001)$; In women, grip strength is lower than $18.20 \mathrm{~kg}$, the strength is weaker, Sensitivity is $53.3 \%$ and Specificity is $78.1 \%$, the AUC is $0.703(\mathrm{p}<0.001)$.

\section{Discussion}

With age increased, muscle strength may decline in general. Muscle weakness is considered a key element of 
Table 1. General characteristics of the study population.

\begin{tabular}{|c|c|c|c|}
\hline & Men & Women & Total \\
\hline $\mathbf{n}$ & 596 & 721 & 1317 \\
\hline Age & $68 \pm 7$ & $66 \pm 6$ & $67 \pm 6$ \\
\hline Height, cm & $170.4 \pm 6.3$ & $157.6 \pm 6.5$ & $163.4 \pm 9.0$ \\
\hline Weight, kg & $72.9 \pm 10.1$ & $63 \pm 11$ & $67.5 \pm 11.9$ \\
\hline sitting time, $h$ & $4.0 \pm 2.4$ & $4.5 \pm 2.6$ & $4.3 \pm 2.54$ \\
\hline IPAQ, MET & $2772(1386,6888)$ & $2373(1386,5446)$ & $2772(1386,5838)$ \\
\hline BMI, kg/m² & $24.9 \pm 3.7$ & $25.2 \pm 4.1$ & $25.1 \pm 3.9$ \\
\hline \multicolumn{4}{|l|}{ Somking status, n (\%) } \\
\hline None & $198(33.2)$ & $421(58.4)$ & $619(47.0)$ \\
\hline current & 244 (40.9) & 213 (29.5) & 457 (34.7) \\
\hline Ex-smoker & $148(24.8)$ & $76(10.5)$ & $224(17.0)$ \\
\hline \multicolumn{4}{|l|}{ Drinking status, n (\%) } \\
\hline None & $193(32.4)$ & $654(90.7)$ & $203(15.4)$ \\
\hline Current & 146 (24.5) & $10(1.4)$ & $185(14.0)$ \\
\hline Occasionally & 115 (19.3) & $39(5.4)$ & $122(9.3)$ \\
\hline Ex-drinking & $136(22.8)$ & $7(1.0)$ & $790(60.0)$ \\
\hline \multicolumn{4}{|l|}{ physial performance } \\
\hline grip strength, kg & $34.5 \pm 7.5$ & $21.1 \pm 5.2$ & $27.2 \pm 9.2$ \\
\hline 4m-walking speed, $\mathrm{m} / \mathrm{s}$ & $1.03 \pm 0.21$ & $0.95 \pm 0.19$ & $0.98 \pm 0.2$ \\
\hline grip strength & $1.39 \pm 3.12$ & $0.85 \pm 0.24$ & $1.08 \pm 0.39$ \\
\hline \multicolumn{4}{|l|}{ Blood sampale } \\
\hline TG, mmol/L & $1.23(0.86,1.72)$ & $1.48(1.12,2.06)$ & $1.38(1.0,1.89)$ \\
\hline TC, $\mathrm{mmol} / \mathrm{L}$ & $4.58(3.99,5.13)$ & $5.11(4.52,5.85)$ & $4.87(4.28,5.61)$ \\
\hline GLU, mmol/L & $5.38(4.98,5.96)$ & $5.41(4.96,6.09)$ & $5.39(4.97,6.03)$ \\
\hline SBP, mmHg & $126 \pm 12$ & $126 \pm 13$ & $126 \pm 13$ \\
\hline DBP, mmHg & $79 \pm 6$ & $79 \pm 6$ & $79 \pm 6$ \\
\hline \multicolumn{4}{|l|}{ FALL, n (\%) } \\
\hline Yes & $68(33.1)$ & $144(39.8)$ & $212(36.8)$ \\
\hline No & 399 (66.9) & $434(60.2)$ & $833(63.2)$ \\
\hline \multicolumn{4}{|l|}{ Disease history } \\
\hline \multicolumn{4}{|l|}{ Diabetes mellitus, n (\%) } \\
\hline Yes & $63(10.6)$ & $130(18.0)$ & $193(14.7)$ \\
\hline No & $527(88.4)$ & $588(81.6)$ & 1115 (84.7) \\
\hline \multicolumn{4}{|l|}{ Hypertention, n (\%) } \\
\hline Yes & 241 (40.4) & 388 (53.8) & $629(47.8)$ \\
\hline
\end{tabular}




\section{Continued}

$\begin{array}{llll}\text { No } & 346(58.1) & 326(45.2) & 672(51.0)\end{array}$

Hyperlipidemia, n (\%)

$\begin{array}{llll}\text { Yes } & 172(28.9) & 303(42.0) & 475(36.1) \\ \text { No } & 419(70.3) & 414(57.4) & 833(63.2)\end{array}$

Hepatopathy, n (\%)

Yes $19(3.2)$

$434(72.8)$

No

557 (77.3)

$99(75.2)$

Nephropathy, n (\%)

$\begin{array}{lrrr}\text { Yes } & 15(2.5) & 12(1.7) & 27(2.1) \\ \text { No } & 437(73.3) & 571(79.2) & 1008(76.5)\end{array}$

Limitation, n (\%)

$\begin{array}{lrrr}\text { Yes } & 79(13.3) & 135(18.7) & 214(16.2) \\ \text { No } & 517(86.7) & 586(81.3) & 1103(83.8)\end{array}$

BMI: Body Mass Index; SBP: Systolic blood pressure; SDP: Diastolic blood pressure.

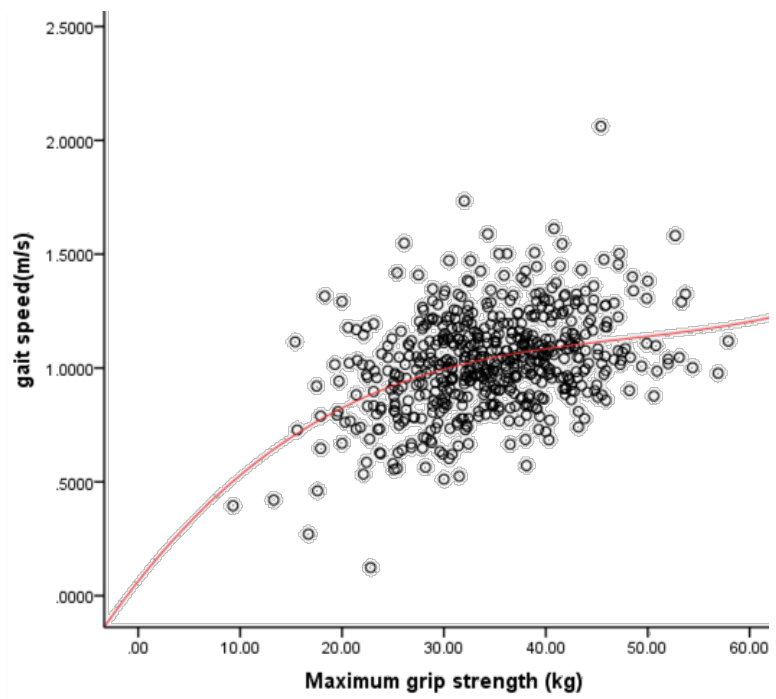

(a)

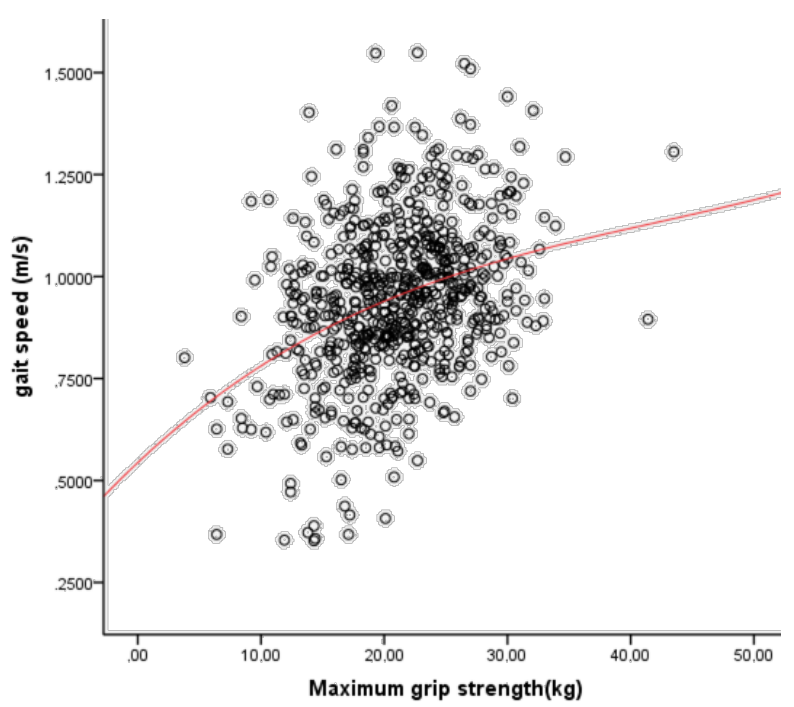

(b)

Figure 1. The association between grip strength and gait speed in men and women. (a) Men ( $\mathrm{n}=596)$; (b) Women ( $\mathrm{n}=721$ ).

frailty [2] and, increasingly, of sarcopenia. The decrease in muscle mass and strength in the elderly has been associated with multiple adverse events, such as physical disability, quality of life, the rate of patient's hospitalization and mortality [8] [9]. Maximum grip strength can well reflect systemic muscle strength.

Mobility activity can better reflect health status and physical function in elderly, $4 \mathrm{~m}$ walking speed at ordinary speed is a simple and effective way, which can better evaluate mobility activity well. In general, 4-m walking speed is lower than $0.8 \mathrm{~m} / \mathrm{s}$ is considered to have mobility limitation in the older population. Previous study showed that it had significant correlation between muscle strength and walking speed in the elderly, which is consistent with us, therefore, mobility limitation was selected as the target variables in this study. In man, grip strength is lower than $32.45 \mathrm{~kg}$, the strength is weaker, In women, grip strength is lower than $18.20 \mathrm{~kg}$, the strength is weaker. However, one cross-sectional study about test-retest reliability and cutoff for subjective weakness of using the hands in heavy tasks, Optimum cutoff values of grip strength were 28.5 and $18.5 \mathrm{~kg}$ for 
Table 2. AUC and cut-Off point of grip strength in the subjects.

\begin{tabular}{|c|c|c|c|c|c|}
\hline & AUC (95\%CI) & p-value & Cut-off & Sensitivity (\%) & Specificity (\%) \\
\hline \multicolumn{6}{|l|}{ Men } \\
\hline & $0.764(0.708,0.821)$ & $<0.001$ & 32.45 & 79.7 & 64.9 \\
\hline \multicolumn{6}{|l|}{ Women } \\
\hline & $0.703(0.655,0.721)$ & $<0.001$ & 18.20 & 53.3 & 78.1 \\
\hline
\end{tabular}

men and women, respectively [10]. This is mainly because the target variables is different, the ability to perform heavy tasks, such as heavy housework or lifting and carrying an 11-kg object was selected as the target variables in previous study, while mobility limitation was selected as the target variables in this study.

Our study has several limitations. First, it was a cross-sectional study, and thus we could not conclude whether muscle strength decline led to increased rate of mobility limitation. Therefore, further study should be undertaken to elucidate this relationship; Second, as the assessments were performed in a public facility, participants were more likely to be active and healthy. The level of grip strength is higher in people generally. Therefore, our results might not be fully representative of the general elderly population.

In summary, when considering muscle weakness in elderly, grip strength in men and women is lower than $32.45 \mathrm{~kg}$ and 18.20. Cutpoints for weakness derived from this large, diverse sample of older adults may be useful to identify populations who may benefit from interventions to improve muscle strength and function.

\section{References}

[1] Manini, T.M. and Clark, B.C. (2012) Dynapenia and Aging: An Update. The Journals of Gerontology Series A, Biological Sciences and Medical Sciences, 67, 28-40. http://dx.doi.org/10.1093/gerona/glr010

[2] Bandeen-Roche, K., Xue, Q.L. and Ferrucci, L. (2006) Phenotype of Frailty: Characterization in the Women's Health and Aging Studies. The Journals of Gerontology Series A, Biological Sciences and Medical Sciences, 61, 262-266. http://dx.doi.org/10.1093/gerona/61.3.262

[3] Cruz-Jentoft, A.J., Baeyens, J.P., Bauer, J.M., et al. (2010) European Working Group on Sarcopenia in Older People. Sarcopenia: European Consensus on Definition and Diagnosis: Report of the European Working Group on Sarcopenia in Older People. Age and Ageing, 39, 412-423. http://dx.doi.org/10.1093/ageing/afq034

[4] Alley, D.E., Shardell, M.D., Peters, K.W., et al. (2014) Grip Strength Cutpoints for the Identification of Clinically Relevant Weakness. The Journals of Gerontology Series A, Biological Sciences and Medical Sciences, 69, 559-566. http://dx.doi.org/10.1093/gerona/glu011

[5] Seeman, T.E., Charpentier, P.A. and Beerkman, L.F. (1994) Predicting Changes in Physical Performance in a HighFunctioning Elderly Cohort: MacArthur Studies of Successful Aging. Journals of Gerontology, 49, M97-M108. http://dx.doi.org/10.1093/geronj/49.3.M97

[6] Abellan van Kan, G., Rolland, Y., Andrieu, S., et al. (2009) Gait Speed at Usual Pace as a Predictor of Adverse Outcomes in Community Dwelling Older People an International Academy on Nutrition and Aging (IANA) Task Force. The Journal of Nutrition, Health \& Aging, 13, 881-889. http://dx.doi.org/10.1007/s12603-009-0246-Z

[7] Studenski, S., Perera, S. and Patel, K. (2011) Gait Speed and Survival in Older Adults. JAMA: The Journal of the American Medical Association, 305, 50-58. http://dx.doi.org/10.1001/jama.2010.1923

[8] Abizanda, P., Navarro, J.L., García-Tomás, M.L., et al. (2012) Validity and Usefulness of Hand-Held Dynamometry for Measuring Muscle Strength in Community-Dwelling Older Persons. Archives of Gerontology and Geriatrics, 54, 21-27. http://dx.doi.org/10.1016/j.archger.2011.02.006

[9] Lahousse, L., Maes, B., Ziere, G., et al. (2014) Adverse Outcomes of Frailty in the Elderly: The Rotterdam Study. European Journal of Epidemiology, 29, 419-427. http://dx.doi.org/10.1007/s10654-014-9924-1

[10] Wang, C.Y. and Chen, L.Y. (2010) Grip Strength in Older Adults: Test-Retest Reliability and Cutoff for Subjective Weakness of Using the Hands in Heavy Tasks. Archives of Physical Medicine and Rehabilitation, 91, 1747-1751. http://dx.doi.org/10.1016/j.apmr.2010.07.225 